\title{
Effects of liraglutide on obesity-associated functional hypogonadism in men
}

\author{
M Jensterle ${ }^{1}$, A Podbregar ${ }^{2}$, K Goricar ${ }^{3}$, N Gregoric ${ }^{1}$ and A Janez $^{1}$ \\ 'Department of Endocrinology, Diabetes and Metabolic Diseases, University Medical Centre Ljubljana, Ljubljana, Slovenia \\ 2University Rehabilitation Institute Republic of Slovenia, Ljubljana, Slovenia \\ ${ }^{3}$ University of Ljubljana, Faculty of Medicine, Institute of Biochemistry, Pharmacogenetics Laboratory, Ljubljana, Slovenia
}

Correspondence should be addressed to A Janez: andrej.janez@kclj.si

\begin{abstract}
Lifestyle measures (LSMs) should be the first-line approach offered for obesity-related functional hypogonadism (FH). When LSMs fail, the role of testosterone replacement treatment (TRT) is unclear. GLP1 receptor agonist liraglutide is linked to progressive and sustained weight loss. A potential direct impact of GLP1 on hypothalamus-pituitarytesticular (HPT) axis was reported in animal models. We aimed to compare the effects of liraglutide and TRT on FH in obese men that had been poor responders to LSM, by means of reversal of $\mathrm{FH}$ and weight reduction. We designed a 16-week prospective randomized open-label study with 30 men (aged $46.5 \pm 10.9$ years, BMI $41.2 \pm 8.4 \mathrm{~kg} / \mathrm{m}^{2}$, mean \pm S.D.) that were randomized to liraglutide $3.0 \mathrm{mg}$ QD (LIRA) or $50 \mathrm{mg}$ of $1 \%$ transdermal gel QD (TRT). Sexual function and anthropometric measures were assessed. Fasting blood was drawn for determination of endocrine and metabolic parameters followed by OGTT. Model-derived parameters including $\mathrm{HOMA}_{\mathrm{IR}}$ and calculated free testosterone (CFT) were calculated. Total testosterone significantly increased in both arms (+5.9 \pm 7.2 in TRT vs $+2.6 \pm 3.5 \mathrm{nmol} / \mathrm{L}$ in LIRA) and led to improved sexual function. LIRA resulted in a significant increase of luteinizing hormone (LH) and follicle-stimulating hormone (FSH) $(P<0.001$ for between-treatment effect). Subjects treated with LIRA lost on average $7.9 \pm 3.8 \mathrm{~kg}$ compared with a $0.9 \pm 4.5 \mathrm{~kg}$ loss in TRT $(P<0.001)$. Metabolic syndrome was resolved in two patients in LIRA and in no subjects in TRT. Liraglutide was superior to TRT in improving an overall health benefit in men with obesity-associated FH after LSM failed.

\author{
Key Words \\ - liraglutide \\ - GLP1 receptor agonist \\ - obesity \\ - functional hypogonadism
}

\section{Introduction}

Obesity causes functional hypogonadism (FH) due to suppression of hypothalamus-pituitary-testicular (HPT) axis that is potentially reversible (1). Recent evidence suggests that weight reduction (WR) with lifestyle measures (LSMs) should be recommended as the first-line approach $(2,3)$, yet in clinical practice LSM often fails. On the other hand, testosterone replacement therapy (TRT) appears to improve body composition and glycometabolic profile without clearly affecting weight lost as well as its role after a trail of unsuccessful LSM is unclear. Only few studies to date reported that combination of TRT and LSM is superior to LSM alone in increasing insulin sensitivity, glycemic control, muscle mass and reducing liver fat $(4,5)$. One study in middle-aged obese men with low testosterone subjected to a rigorous weight loss program has reported that men not receiving TRT lost adipose tissue and lean body mass, whereas weight loss in testosterone-treated men was almost exclusively due to loss of body fat (6). In selected patients, TRT could be started concomitantly or in addition to LSM to augment the benefits of LSM, although the quality of evidence supporting this concept is low (2).

GLP1 receptor agonists are linked to progressive and sustained weight loss in subjects with or without

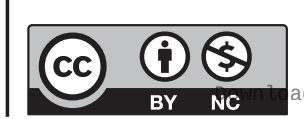


diabetes (7). Despite the fact that the prevalence of $\mathrm{FH}$ in obese male population is increased by 13 -fold (8), the impact of liraglutide on obesity-related $\mathrm{FH}$ has not yet been addressed in a prospective clinical study. There was only one retrospective observational study reporting that adding long-acting GLP1 receptor agonist liraglutide to LSM, metformin and TRT boosted erectile function in obese men with type 2 diabetes and different forms of hypogonadism (9). Furthermore, some animal models have demonstrated that GLP1 might even have a direct impact on HPT that is beyond WR $(10,11,12,13,14)$. These observations provided an additional rationale to evaluate the effect of liraglutide on male obesityassociated $\mathrm{FH}$.

The aim of this pilot study was to compare the effects of short-term intervention with liraglutide in an antiobesity dose and TRT on FH and weight loss in obese men who had been poor responders to LSM, by means of reversal of $\mathrm{FH}$ and WR. The primary outcome measures were changes in testosterone, sexual function and gonadotropins. The secondary outcomes were measures of obesity and metabolic profile.

\section{Materials and methods}

\section{Subjects}

Thirty middle-aged obese men with $\mathrm{FH}$ (aged $46.5 \pm 10.9$ years, BMI $41.2 \pm 8.4 \mathrm{~kg} / \mathrm{m}^{2}$, mean \pm s.D.) who had been previously poor responders to LSM, by means of WR and recovery of $\mathrm{FH}$, were included in the study. They were eligible for enrolment if they were 18-65 years old, obese (BMI $\left.\geq 30 \mathrm{~kg} / \mathrm{m}^{2}\right)$ and had been diagnosed with FH. FH was diagnosed as consistently low serum total testosterone below $11 \mathrm{nmol} / \mathrm{L}$ on at least two separate morning measurements after an overnight fast in addition to at least two symptoms of sexual dysfunction and low or inappropriately normal gonadotropin levels. Specific pathologic etiologies suppressing the HPT axis such as hyperprolactinemia and endogenous Cushing syndrome were excluded. Evaluation of other pituitary hormones and pituitary MRI to exclude hypopituitarism and/or pituitary or hypothalamic tumor or infiltrative disease was performed when it was clinically indicated (15). Other exclusion criteria were iron overload, history of carcinoma, venous thromboembolism, thrombophilia, known preexisting cardiovascular disease or stroke, initial PSA more than $3 \mathrm{ng} / \mathrm{L}$, severe lower urinary tract symptoms with an International Prostate Symptom Score (IPSS) $>19$, untreated sleep apnea, initial hematocrit more than 50\%, significant kidney or liver disease, active desire for fertility, opioids or glucocorticoids use and personal or family history of MEN 2.

All subjects were informed of the study aims and provided written consent before entering the study, which was conducted in accordance with the Declaration of Helsinki and approved by the National Ethical Committee. The study is registered with ClinicalTrials.gov identifier: NCT03619330.

\section{Study protocol}

We conducted a 16-week prospective randomized openlabel study with 30 eligible men who were randomized to liraglutide $3.0 \mathrm{mg}$ QD s.c. (LIRA arm) and $50 \mathrm{mg}$ of $1 \%$ transdermal gel QD (TRT arm). Liraglutide was initiated with a dose of $0.6 \mathrm{mg}$ injected s.c. once per day and weekly titrated up to $3 \mathrm{mg}$. At the beginning of the study, LSM was again actively promoted in both groups. A reduced intake of $500-800 \mathrm{kcal} /$ day and a diet consisting of up to $50 \%$ of carbohydrates preferably with low glycemic index, 20\% of proteins and 30\% of fat, mostly mono- and polyunsaturated, with the amount of saturated fat less than $10 \%$, was advised. The participants were encouraged to increase consumption of fibers, whole grains, cereals, fruits and vegetables along with at least $30 \mathrm{~min}$ of moderate-intensity physical activity daily.

\section{Methods}

All patients underwent clinical, anthropometric and biochemical assessment at baseline and at study end point.

\section{Assessment of symptoms and signs of $\mathrm{FH}$}

We assessed sexual function through a self-reported evaluation of both the number of morning erections per week and the number of ejaculations per week as well as a self-reported measurement of libido. Libido was defined and scaled as 1 for very poor, 2 for poor and 3 for good. A questionnaire, aging male syndrome (AMS) scale, was collected and analyzed before and at the end of the study. Translation of Slovene version was performed in congruence with international methodological recommendations for linguistic and cultural adaptation
This work is licensed under a Creative Commons Attribution-NonCommercial 4.0 International License. ded from Bioscientifica.com at $04 / 26 / 2023$ 02:14:45AM via free access 
of HRQoL measures using the English version as source language to ensure cross-cultural equivalence among countries. Six steps of the translation process were followed as recommended (16).

\section{Assessment of endocrine parameters}

Total testosterone levels were measured by coated tube RIA (DiaSorin S. p. A., Salluggia, Italy and Diagnostic Products Corporation, Los Angeles, CA, USA, respectively). Within and between assays, coefficients of variation for testosterone were 1.05 and $5.75 \%$. Sex hormone-binding globulin (SHBG), luteinizing hormone (LH) and follicle-stimulating hormone (FSH) were determined with a chemiluminescent immunoassay (Immulite 2000 XPi Analyzer; Siemens Healthcare). Within and between assays, coefficients of variation for the applied method ranged from 1.2 to $4.0 \%$ and 1.8 to $4.3 \%$. Calculated free testosterone (cFT) and bioavailable testosterone were derived from the calculator at http://www.issam.ch/freetesto.htm (accessed 7/10/2018) (17).

\section{Assessment of anthropometric parameters}

Height, weight and waist circumference were measured at the baseline and at study end point. Waist circumference was measured in a standing position midway between the lower costal margin and the iliac crest. BMI was calculated as the weight in kilograms divided by square of height in meters.

\section{Assessment of metabolic parameters}

Glucose levels were determined using the standard glucose oxidase method (Beckman Coulter Glucose Analyzer; Beckman Coulter Inc., CA, USA). Insulin was determined by immunoradiometric assay (Biosource Europe S.A., Nivelles, Belgium). Within and between assays, coefficients of variation for insulin were 3.6 and $3.8 \%$. HbA1 was assessed by high-performance liquid chromatography (D-100; Bio-Rad Laboratories). Within and between assays, coefficients of variation for $\mathrm{HbA1c}$ were 1.67 and $2.27 \%$. Lipids were determined using Adiva 1800, Siemens analyzer. Insulin resistance (IR) was calculated by the homeostasis model assessment for IR $\left(\mathrm{HOMA}_{\mathrm{IR}}\right)$ : fasting serum insulin $(\mathrm{mU} / \mathrm{L}) \times$ fasting plasma glucose $(\mathrm{mmol} / \mathrm{L}) / 22.5$ (18). Impaired glucose tolerance (IGT) was identified by $2 \mathrm{~h}$ glucose levels between
7.8 and $11.0 \mathrm{mmol} / \mathrm{L}$, as defined by the American Diabetes Association criteria (19).

Comorbid conditions included self-reported heart condition, diabetes, cancer, liver conditions, kidney conditions, prostate disease and thyroid disorders. The self-reported history was checked and completed by available medical records.

Safety parameters (complete blood count, PSA, markers of hepatic and renal functions and serum electrolytes) were assessed before and after 16 weeks of study treatment. All men were instructed to report any side effects during the treatment.

\section{Statistical analysis}

The results for continuous variables are presented as means \pm s.D. Wilcoxon signed-rank test was used for comparison of related samples such as pre- and posttreatment values, while Mann-Whitney test was used for comparison of independent groups. $P$ values below 0.05 were considered statistically significant. Statistical analysis was performed using IBM SPSS Statistics, version 21 (IBM Corp).

\section{Results}

Baseline characteristics of the study population are provided in Table 1 . The mean age of participants was $49.3 \pm 9.8$ years in TRT and $43.9 \pm 11.6$ years in LIRA arm. There were no significant differences at baseline in any of the parameters between the treatment groups.

\section{Symptoms and signs of $\mathrm{FH}$}

Libido and sexual functions were significantly improved in both arms. In TRT arm, libido as reported by selfmeasurement increased from $1.0 \pm 0.0$ to $2.2 \pm 0.7$ scores $(P=0.003)$. In LIRA, libido increased from $1.1 \pm 0.3$ to $1.8 \pm 0.6$ scores $(P=0.003)$. The number of morning erections per week as reported by self-evaluation increased from $1.4 \pm 1.3$ to $3.8 \pm 2.6 \mathrm{~N} /$ week in TRT $(P=0.012)$ and from $1.4 \pm 2.2$ to $2.9 \pm 2.5 \mathrm{~N} /$ week in LIRA $(P=0.017)$. Ejaculations per week increased from $0.9 \pm 1.0$ to $3.3 \pm 2.2 \mathrm{~N} /$ week $(P=0.008)$ in TRT and from $2.6 \pm 2.8$ to $3.8 \pm 2.9 \mathrm{~N} /$ week in LIRA $(P=0.048)$. There were no significant between-treatment differences for any parameters $(P=0.762$ for libido, $P=0.550$ for morning erections, $P=0.204$ for ejaculations). AMS score was significantly improved in TRT (Table 1).
This work is licensed under a Creative Commons Attribution-NonCommercial 4.0 International License. ded from Bioscientifica.com at 04/26/2023 02:14:45AM via free access 
Table 1 Pre- and posttreatment characteristics of patients treated with TRT $(N=15)$ and liraglutide $(N=15)$.

\begin{tabular}{|c|c|c|c|c|c|c|c|}
\hline \multirow[b]{2}{*}{ Characteristics } & \multicolumn{3}{|c|}{ TRT } & \multicolumn{3}{|c|}{ Liraglutide } & \multirow{2}{*}{$\begin{array}{c}\text { Comparison of } \\
\text { pretreatment } \\
\text { values }\end{array}$} \\
\hline & Pretreatment & Posttreatment & $P$ & Pretreatment & Posttreatment & $P$ & \\
\hline Weight (kg) & $123 \pm 29$ & $122 \pm 29$ & 0.332 & $134 \pm 18$ & $126 \pm 18$ & 0.001 & 0.239 \\
\hline $\mathrm{BMI}\left(\mathrm{kg} / \mathrm{m}^{2}\right)$ & $39 \pm 9$ & $38.8 \pm 9.2$ & 0.363 & $43.2 \pm 7.5$ & $40.6 \pm 7.5$ & 0.001 & 0.185 \\
\hline Total testosterone (nmol/L) & $7.2 \pm 3.2$ & $13.1 \pm 8.1$ & 0.005 & $7.6 \pm 1.5$ & $10.2 \pm 4.2$ & 0.048 & 0.458 \\
\hline $\begin{array}{l}\text { Calculated free testosterone } \\
(\mathrm{nmol} / \mathrm{L})\end{array}$ & $0.17 \pm 0.07$ & $0.30 \pm 0.25$ & 0.099 & $0.17 \pm 0.04$ & $0.22 \pm 0.08$ & 0.155 & 0.979 \\
\hline $\begin{array}{l}\text { Calculated bioavailable } \\
\text { testosterone (nmol/L) }\end{array}$ & $4.28 \pm 1.68$ & $7.67 \pm 6.19$ & 0.084 & $4.33 \pm 1.03$ & $5.15 \pm 2.12$ & 0.182 & 0.852 \\
\hline AMS & $40.6 \pm 9.9$ & $31.5 \pm 5.7$ & 0.002 & $43.4 \pm 12.4$ & $37.6 \pm 12.3[1]$ & 0.157 & 0.616 \\
\hline LH (IU/L) & $3.1 \pm 1.3$ & $1.1 \pm 1.3$ & 0.004 & $2.7 \pm 1.2$ & $3.4 \pm 1.1$ & 0.048 & 0.291 \\
\hline $\mathrm{FSH}(\mathrm{mIU} / \mathrm{L})$ & $5.6 \pm 2.5[1]$ & $2.4 \pm 2.1[1]$ & 0.002 & $4 \pm 1.7$ & $4.9 \pm 2.1$ & 0.031 & 0.089 \\
\hline SHBG (nmol/L) & $20.2 \pm 5.4$ & $20.8 \pm 6.2$ & 0.968 & $26.3 \pm 13.6$ & $29.3 \pm 14.1$ & 0.063 & 0.239 \\
\hline Waist circumference (cm) & $125 \pm 23[1]$ & $124 \pm 22$ & 0.136 & $128 \pm 14[1]$ & $124 \pm 15$ & 0.010 & 0.295 \\
\hline BP systolic (mmHg) & $150 \pm 16[1]$ & $143 \pm 18$ & 0.023 & $144 \pm 12[1]$ & $138 \pm 13[1]$ & 0.387 & 0.611 \\
\hline BP diastolic (mmHg) & $92 \pm 10[1]$ & $88 \pm 17$ & 0.065 & $88 \pm 13[1]$ & $87 \pm 10[1]$ & 0.074 & 0.470 \\
\hline Glu 0 min OGTT (mmol/L) & $8.1 \pm 3.2$ & $6.8 \pm 2.3$ & 0.294 & $6.2 \pm 1.1$ & $5.8 \pm 0.7$ & 0.102 & 0.202 \\
\hline Glu 120 min OGTT (mmol/L) & $9.2 \pm 5[3]$ & $8.9 \pm 3.9[3]$ & 0.944 & $7.4 \pm 3.1$ & $6.4 \pm 2.2[1]$ & 0.196 & 0.437 \\
\hline Insulin 0 min OGTT (mU/L) & $24.7 \pm 13.3$ & $17.9 \pm 8.4[2]$ & 0.016 & $31.6 \pm 19.4[1]$ & $29 \pm 18.9[2]$ & 0.556 & 0.287 \\
\hline Insulin 120 min OGTT (mU/L) & $77.7 \pm 43.3[2]$ & $65.7 \pm 31.8[2]$ & 0.091 & $131.3 \pm 91.5[1]$ & $140.5 \pm 146.2[3]$ & 0.477 & 0.093 \\
\hline $\mathrm{HOMA}_{\mathrm{IR}}$ score & $9.1 \pm 6.4$ & $5.4 \pm 3.3[1]$ & 0.033 & $9 \pm 6.5[1]$ & $7.9 \pm 6[1]$ & 0.754 & 0.880 \\
\hline $\mathrm{HbA1c}(\%)$ & $6.4 \pm 1.3$ & $6.4 \pm 1.1$ & 0.937 & $5.9 \pm 0.8$ & $5.3 \pm 0.4[1]$ & 0.001 & 0.202 \\
\hline Cholesterol (mmol/L) & $5.2 \pm 0.9[1]$ & $5.3 \pm 0.9$ & 0.783 & $4.9 \pm 0.8$ & $4.9 \pm 0.9$ & 0.823 & 0.595 \\
\hline HDL (mmol/L) & $1.1 \pm 0.2[1]$ & $1.1 \pm 0.3[1]$ & 0.903 & $1.1 \pm 0.3[1]$ & $1.1 \pm 0.23$ & 0.952 & 0.247 \\
\hline LDL (mmol/L) & $3.1 \pm 0.8[1]$ & $3.4 \pm 0.8[1]$ & 0.259 & $3.2 \pm 0.7[1]$ & $3.2 \pm 0.9$ & 0.476 & 0.979 \\
\hline TAG (mmol/L) & $2.2 \pm 1.3[1]$ & $2.7 \pm 1.2[1]$ & 0.020 & $1.9 \pm 1.5[1]$ & $2.0 \pm 1.0[1]$ & 0.007 & 0.168 \\
\hline
\end{tabular}

Data presented as mean \pm S.D., $P$ values calculated using Wilcoxon test for related samples, comparison of pretreatment values calculated using Mann-Whitney test. Bold indicates statistical significance. [missing data].

\section{Endocrine changes}

Total testosterone significantly increased in both arms, with no significant differences between groups. SHBG tended to increase in LIRA. There was a significant differential effect on HPT axis resulting in further suppression of LH and FSH in TRT and a significant increase of LH and FSH in LIRA $(P<0.001)$ (Tables 1 and 2).

\section{Measures of obesity}

Subjects treated with liraglutide lost on average $6.0 \pm 3.2 \%$ of initial weight compared with a $0.8 \pm 3.3 \%$ in TRT arm. LIRA was also superior in reduction of BMI and waist circumference (Tables 1 and 2).

\section{Metabolic parameters}

Two men in LIRA and two in TRT had IGT at the beginning of the study. After 16 weeks all of them had normal glucose tolerance. Five patients in LIRA and six patients in TRT had type 2 diabetes at baseline. After 16 months, three patients in LIRA reported lowering of insulin doses.
In TRT one man progressed from normal glucose tolerance to type 2 diabetes mellitus. Ten men in the liraglutide arm and ten in testosterone arm had metabolic syndrome at baseline. It was resolved in two patients in LIRA and in no subjects in TRT.

Hb1Ac significantly decreased in LIRA. HOMA ${ }_{I R}$ score and fasting insulin decreased in TRT. Fasting glucose, glucose and insulin after OGTT, LDL and total cholesterol did not consistently decrease in either group. Triacylglycerol (TAG) significantly increased in both arms and systolic blood pressure (BP) significantly decreased in TRT (Table 1). The between-treatment difference was significant for HbA1c, LIRA being superior to TRT (Table 2).

\section{Adverse events}

In TRT none of the patients reported adverse events. Ht and PSA did not increase significantly in either arm. PSA did not increase for more than $1.4 \mu \mathrm{g} / \mathrm{L}$ in any subjects (from $0.57 \pm 0.33$ to $0.59 \pm 0.36 \mu \mathrm{g} / \mathrm{L}$ in TRT and from $0.93 \pm 0.76$ to $0.88 \pm 0.66 \mu \mathrm{g} / \mathrm{L}$ in LIRA). Ht did not rise over $52 \%$ during either intervention from $0.44 \pm 0.03$ to https://ec.bioscientifica.com

https://doi.org/10.1530/EC-18-0514 (c) 2019 The authors Published by Bioscientifica Ltd
This work is licensed under a Creative Commons Attribution-NonCommercial 4.0 International License. ed from Bioscientifica.com at $04 / 26 / 2023$ 02:14:45AM via free access 
Table 2 Change in patients' clinical characteristics during treatment.

\begin{tabular}{l}
\hline Characteristics \\
\hline Weight (kg) \\
BMI (kg/m²) \\
Total testosterone (nmol/L) \\
Calculated free testosterone (nmol/L) \\
Calculated bioavailable testosterone (nmol/L) \\
AMS \\
LH (IU/L) \\
FSH (mIU/L) \\
SHBG (nmol/L) \\
Waist circumference (cm) \\
BP systolic (mmHg) \\
BP diastolic (mmHg) \\
Glu 0 min OGTT (mmol/L) \\
Glu 120 min OGTT (mmol/L) \\
Insulin 0 min OGTT (mU/L) \\
Insulin 120 min OGTT (mU/L) \\
HOMA IR $_{\text {Score }}$ \\
HbA1c (\%) \\
Cholesterol (mmol/L) \\
HDL (mmol/L) \\
LDL (mmol/L) \\
TAG (mmol/L)
\end{tabular}

\begin{tabular}{c}
\hline TRT \\
$-1 \pm 5$ \\
$-0.3 \pm 1.4$ \\
$5.9 \pm 7.2$ \\
$0.13 \pm 0.25$ \\
$3.43 \pm 6.06$ \\
$-9.1 \pm 7$ \\
$-2 \pm 1.3$ \\
$-3.2 \pm 1.7$ \\
$0.6 \pm 4$ \\
$-2 \pm 4[1]$ \\
$-9 \pm 11[1]$ \\
$-7 \pm 11[1]$ \\
$-1.3 \pm 3$ \\
$0 \pm 2.2[4]$ \\
$-5.9 \pm 6.5[2]$ \\
$-12 \pm 18.9[2]$ \\
$-2.9 \pm 3.9[1]$ \\
$0 \pm 0.8$ \\
$0.1 \pm 0.6[1]$ \\
$0.01 \pm 0.15[2]$ \\
$0.15 \pm 0.49[2]$ \\
$0.37 \pm 0.44[2]$
\end{tabular}

\begin{tabular}{|c|c|}
\hline Liraglutide & $P$ \\
\hline$-8 \pm 4$ & $<0.001$ \\
\hline$-2.6 \pm 1.3$ & $<0.001$ \\
\hline $2.6 \pm 3.5$ & 0.239 \\
\hline $0.04 \pm 0.07$ & 0.551 \\
\hline $0.90 \pm 1.78$ & 0.514 \\
\hline$-4.8 \pm 10.3[1]$ & 0.243 \\
\hline $0.7 \pm 1.2$ & $<0.001$ \\
\hline $0.9 \pm 1.8$ & $<0.001$ \\
\hline $3 \pm 5.3$ & 0.202 \\
\hline$-5 \pm 5[1]$ & 0.035 \\
\hline$-7 \pm 17[1]$ & 0.514 \\
\hline$-4 \pm 6[1]$ & 0.319 \\
\hline$-0.4 \pm 0.8[0]$ & 0.583 \\
\hline$-1.2 \pm 2.8[1]$ & 0.431 \\
\hline$-2.8 \pm 12.2[2]$ & 0.347 \\
\hline$-0.1 \pm 142.4[3]$ & 0.748 \\
\hline$-1.3 \pm 3.7[1]$ & 0.134 \\
\hline$-0.5 \pm 0.5[1]$ & 0.004 \\
\hline $0 \pm 0.5$ & 0.667 \\
\hline $0 \pm 0.17[1]$ & 0.865 \\
\hline$-0.07 \pm 0.36[1]$ & 0.207 \\
\hline $0.3 \pm 0.53[2]$ & 0.525 \\
\hline
\end{tabular}

Data presented as mean \pm S.D., $P$ values calculated using Mann-Whitney test. Bold indicates statistical significance. [missing data].

$0.46 \pm 0.03$ in TRT or from $0.46 \pm 0.04$ to $0.45 \pm 0.03$ in TRT. The most frequent adverse events in LIRA were mild to moderate, transient and gastrointestinal in nature. Nausea was reported by four, headache by one and stomach pain by two patients. None of the patients in LIRA reported hypoglycemic events.

\section{Discussion}

This is the first report demonstrating that 16-week intervention with liraglutide in obese middle-aged men who had been poor responders to LSM, by means of improvement of $\mathrm{FH}$ and WR, improved sexual health and overall health benefit. Treatment with liraglutide in an anti-obesity dose resulted in significant improvement of sexual symptoms, increase in total testosterone concentrations, recovery of HPT axis, reduction of anthropometric measures of obesity and improvement of glycemic control. TRT improved sexual functions, total testosterone levels and $\mathrm{HOMA}_{\mathrm{IR}}$.

In LIRA arm, $6 \%$ of weight loss was related with modest increase of total testosterone with $2.6 \mathrm{nmol} / \mathrm{L}$. The impact of WR on testosterone level in obese men has been evaluated only in few RCT and meta-analysis that was limited to small studies with short-term follow-up and heterogeneous study designs $(3,20)$. Its impact was generally related to the magnitude of WR. Five per cent of weight loss with LSM was associated with the $2 \mathrm{mmol} / \mathrm{L}$ increase of total testosterone and no increase of free testosterone (21), 10\% of LSM induced weight loss with $2.9 \mathrm{nmol} / \mathrm{L}$ increase of total testosterone, weight loss of more than $15 \%$ with increase by $5.7 \mathrm{mmol} / \mathrm{L}$ (21) and 30\% of weight loss after bariatric surgery with the increase of total testosterone by $8.7 \mathrm{nmol} / \mathrm{L}(3,20$, 22 ). The observed magnitude of the increase in total testosterone in our patients who had been treated with liraglutide was slightly greater than expected for the amount of WR, although they remained hypogonadal by laboratory standards. If WR rate would be maintained in LIRA arm then treatment could result in eugonadal numbers with longer follow-up.

In TRT arm, $50 \mathrm{mg}$ of $1 \%$ transdermal gel QD in our study led to moderate increase of total testosterone level by $5.9 \mathrm{nmol} / \mathrm{L}$. The testosterone increase in TRT arm was associated with significant improvement of sexual functions and mood as assessed by AMS score. The observations were in line with other studies reporting that TRT consistently improved sexual functions only in men with significantly reduced total testosterone, as observed in our cohort where mean value of total testosterone at baseline was below $8 \mathrm{nmol} / \mathrm{L}$ (23). Interestingly, in LIRA arm, sexual functions also improved, despite only a modest rise of total testosterone by $2.6 \mathrm{nmol} / \mathrm{L}$.
This work is licensed under a Creative Commons Attribution-NonCommercial 4.0 International License. ded from Bioscientifica.com at 04/26/2023 02:14:45AM via free access 
We hypothesized that mechanisms other than testosterone increase, including psychosocial factors related to improved body image due to significant WR, might play a role in clinically improved sexual symptoms in LIRA arm. In line with this observation, another study reported that the degree of WR predicted improved erectile function, whereas changes in testosterone level did not (24). Since AMS did not significantly improve in LIRA arm this possibly means it has less effect on nonsexual symptoms of testosterone deficiency including mood, fatigue, sleep and well-being.

The suppression of HPT axis in FH associated with obesity is considered to be an adaptive response to the weight variation (25). Indeed, especially the severe form of obesity (BMI>38) is characterized by reduction of serum $\mathrm{T}$, its free fraction and quality and quantity of LH secretion (26). Moreover, several additional causes can have a key role in bringing about this clinical condition (27). Several adipokines were proposed as negative mediators on the reproductive axis (28). IR has a distortive impact on GnRH neurons (29). It has been reported previously that LH increased with WR in magnitude-dependent manner (8). With weight loss of more than $15 \%$ LH increased for 2.2 IU (8). In our study $6 \%$ of WR in LIRA was associated with an increase of LH by $0.7 \mathrm{IU} / \mathrm{L}$ and $\mathrm{FSH}$ by $0.9 \mathrm{mIU} / \mathrm{L}$, whereas both gonadotropins were further suppressed in TRT as expected. Although the current data on GLP1-receptor analogs and reproduction are scarce, some animal studies demonstrated the potential involvement of GLP1 in the direct regulation of the hypothalamus-pituitary system. Intracerebroventricular injection of GLP1 increased the levels of LH in rats (30). Furthermore, in response to fasting, the rats' hypothalamic GLP1 content significantly decreased when there was a rapid reduction in pituitary LH. Upon refeeding period GLP1 increased, perhaps aiding the recovery of LH secretion (14).

LIRA resulted in a significant weight loss of about $6 \%$ in men who had been poor responders to LSM. In agreement with our study the data from SCALE trials reported similar but slightly pronounced weight loss ranging from 5.7\% to $8 \%(31,32,33)$. By contrast, TRT in our study did not result in significant weight or waist circumference reduction. The contribution of TRT to WR is uncertain. While some studies and meta-analyses highlighted that TRT may reduce body weight in obese men $(34,35,36$, 37), few randomized, double-blind placebo controlled trials and a meta-analysis of RCT studies (38) have not confirmed those encouraging results $(15,39,40)$.
As expected, LIRA improved glycemic control resulting in a significant decrease in HbA1c. Metabolic syndrome was resolved in two men treated with LIRA, while no such changes were observed in TRT. However, TRT led to significant improvement of IR as assessed by $\mathrm{HOMA}_{\mathrm{IR}}$. It is known that TRT might decrease IR by means of promoting the commitment of pluripotent stem cells into the myogenic lineage and inhibiting their differentiation into mature adipocyte (41). A compelling number of clinical studies demonstrated that TRT led to improvement in glycemic control and insulin sensitivity $(4,5,37,42)$, whereas some failed to confirm these observations (43).

Our study has some limitations. The conclusions are limited by a small sample size and short-term observation. Further larger studies of longer duration should be powered using these preliminary results. Libido and sexual function were not measured with validated tools, and therefore could be inaccurate. Furthermore, 11 out of 30 subjects had type 2 diabetes that could have an independent impact on HPT axis. However, the presence of type 2 diabetes was balanced between the groups and well controlled throughout the study. We assumed that a complex bidirectional relationship between dysglycemia and HPT was controlled in one direction. However, the main strength of this pilot study is the original concept of comparing TRT and liraglutide as a second-line approach in patients who had been poor responders to LSM. The design addressed a common clinical dilemma that is raised after LSM fails.

In conclusion, the pathophysiological background of $\mathrm{FH}$ supports a rationale for therapy, other than TRT. Body weight loss with LSM should be the first approach offered to obese men with FH. When LSM fails and bariatric surgery is not yet indicated, novel pharmacological anti-obesity strategies with liraglutide should be advised over TRT, by means of overall health improvement. We demonstrated that liraglutide had modest effect on testosterone levels, potential to improve sexual symptoms irrespective of modest increase in total testosterone, reversed the HPT axis suppression, reduced weight and waist circumference and improved glycemic control. Future studies should investigate the complex relationship between WR and FH beyond the mere impact of the magnitude of WR. Comparing different approaches for WR, including diet, exercises, GLP1 receptor agonists and bariatric surgery, might additionally enlighten the complex cross talks among gut, brain and reproductive axis.

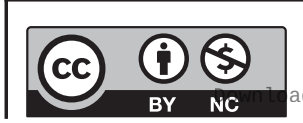

This work is licensed under a Creative Commons Attribution-NonCommercial 4.0 International License. ded from Bioscientifica.com at 04/26/2023 02:14:45AM 


\section{Declaration of interest}

The authors declare that there is no conflict of interest that could be perceived as prejudicing the impartiality of the research reported.

\section{Funding}

The study was supported by the grant number P3-0298 of the University Medical Center, Ljubljana, Slovenia.

\section{Acknowledgements}

The authors appreciate the kind assistance of nurses Mirela Ozura, Melita Dolenc and Elizabeta Stepanović at the Department of Endocrinology, Diabetes and Metabolic Diseases.

\section{References}

1 Wu FC, Tajar A, Pye SR, Silman AJ, Finn JD, O’Neill TW, Bartfai G, Casanueva F, Forti G, Giwercman A, et al. Hypothalamic-pituitarytesticular axis disruptions in older men are differentially linked to age and modifiable risk factors: the European Male Aging Study. Journal of Clinical Endocrinology and Metabolism 200893 2737-2745. (https://doi.org/10.1210/jc.2007-1972)

2 Grossmann M \& Matsumoto AM. A perspective on middle-aged and older men with functional hypogonadism: focus on holistic management. Journal of Clinical Endocrinology and Metabolism 2017 102 1067-1075. (https://doi.org/10.1210/jc.2016-3580)

3 Corona G, Rastrelli G, Monami M, Saad F, Luconi M, Lucchese M, Facchiano E, Sforza A, Forti G, Mannucci E, et al. Body weight loss reverts obesity-associated hypogonadotropic hypogonadism: a systematic review and meta-analysis. European Journal of Endocrinology 2013168 829-843. (https://doi.org/10.1530/EJE-12-0955)

4 Heufelder AE, Saad F, Bunck MC \& Gooren L. Fifty-two-week treatment with diet and exercise plus transdermal testosterone reverses the metabolic syndrome and improves glycemic control in men with newly diagnosed type 2 diabetes and subnormal plasma testosterone. Journal of Andrology 200930 726-733. (https://doi. org/10.2164/jandrol.108.007005)

5 Hoyos CM, Yee BJ, Phillips CL, Machan EA, Grunstein RR \& Liu PY. Body compositional and cardiometabolic effects of testosterone therapy in obese men with severe obstructive sleep apnoea: a randomised placebo-controlled trial. European Journal of Endocrinology 2012167 531-541. (https://doi.org/10.1530/EJE-12-0525)

$6 \mathrm{Ng}$ Tang Fui M, Prendergast LA, Dupuis P, Raval M, Strauss BJ, Zajac JD \& Grossmann M. Effects of testosterone treatment on body fat and lean mass in obese men on a hypocaloric diet: a randomised controlled trial. BMC Medicine 201614 153. (https://doi.org/10.1186/ s12916-016-0700-9)

7 Vilsboll T, Christensen M, Junker AE, Knop FK \& Gluud LL. Effects of glucagon-like peptide-1 receptor agonists on weight loss: systematic review and meta-analyses of randomised controlled trials. BMJ 2012 344 d7771. (https://doi.org/10.1136/bmj.d7771)

8 Ponce OJ, Spencer-Bonilla G, Alvarez-Villalobos N, Serrano V, Singh-Ospina N, Rodriguez-Gutierrez R, Salcido-Montenegro A, Benkhadra R, Prokop LJ, Bhasin S, et al. The efficacy and adverse events of testosterone replacement therapy in hypogonadal men: A systematic review and meta-analysis of randomized, placebocontrolled trials. Journal of Clinical Endocrinology and Metabolism 2018 103 1745-1754. (https://doi.org/10.1210/jc.2018-00404)

9 Giagulli VA, Carbone MD, Ramunni MI, Licchelli B, De Pergola G, Sabba C, Guastamacchia E \& Triggiani V. Adding liraglutide to lifestyle changes, metformin and testosterone therapy boosts erectile function in diabetic obese men with overt hypogonadism. Andrology 20153 1094-1103. (https://doi.org/10.1111/andr.12099)

10 MacLusky NJ, Cook S, Scrocchi L, Shin J, Kim J, Vaccarino F, Asa SL \& Drucker DJ. Neuroendocrine function and response to stress in mice with complete disruption of glucagon-like peptide-1 receptor signaling. Endocrinology 2000141 752-762. (https://doi.org/10.1210/ endo.141.2.7326)

11 Garris DR. Diabetes (db/db) mutation-induced endometrial epithelial lipoapoptosis: ultrastructural and cytochemical analysis of reproductive tract atrophy. Reproductive Biology and Endocrinology 20053 15. (https://doi.org/10.1186/1477-7827-3-15)

12 Artunc-Ulkumen B, Pala HG, Pala EE, Yavasoglu A, Yigitturk G \& Erbas O. Exenatide improves ovarian and endometrial injury and preserves ovarian reserve in streptozocin induced diabetic rats. Gynecological Endocrinology 201531 196-201. (https://doi.org/10.310 9/09513590.2014.975686)

13 Bethel MA, Patel RA, Merrill P, Lokhnygina Y, Buse JB, Mentz RJ, Pagidipati NJ, Chan JC, Gustavson SM, Iqbal N, et al. Cardiovascular outcomes with glucagon-like peptide-1 receptor agonists in patients with type 2 diabetes: a meta-analysis. Lancet Diabetes and Endocrinology 20186 105-113. (https://doi.org/10.1016/S22138587(17)30412-6)

14 Greco D. Normal pregnancy outcome after first-trimester exposure to liraglutide in a woman with type 2 diabetes. Diabetic Medicine 2015 32 e29-e30. (https://doi.org/10.1111/dme.12726)

15 Bhasin S, Cunningham GR, Hayes FJ, Matsumoto AM, Snyder PJ, Swerdloff RS, Montori VM \& Task Force, Endocrine Society. Testosterone therapy in men with androgen deficiency syndromes: an Endocrine Society clinical practice guideline. Journal of Clinical Endocrinology and Metabolism 201095 2536-2559. (https://doi. org/10.1210/jc.2009-2354)

16 Heinemann LA, Saad F, Zimmermann T, Novak A, Myon E, Badia X, Potthoff P, T'Sjoen G, Pollanen P, Goncharow NP, et al. The Aging Males' Symptoms (AMS) scale: update and compilation of international versions. Health and Quality of Life Outcomes 2003115. (https://doi.org/10.1186/1477-7525-1-15)

17 Vermeulen A, Verdonck L \& Kaufman JM. A critical evaluation of simple methods for the estimation of free testosterone in serum. Journal of Clinical Endocrinology and Metabolism 199984 3666-3672. (https://doi.org/10.1210/jcem.84.10.6079)

18 Matthews DR, Hosker JP, Rudenski AS, Naylor BA, Treacher DF \& Turner RC. Homeostasis model assessment: insulin resistance and beta-cell function from fasting plasma glucose and insulin concentrations in man. Diabetologia 198528 412-419. (https://doi. org/10.1007/BF00280883)

19 Genuth S, Alberti KG, Bennett P, Buse J, Defronzo R, Kahn R, Kitzmiller J, Knowler WC, Lebovitz H, Lernmark A, et al. Follow-up report on the diagnosis of diabetes mellitus. Diabetes Care 200326 3160-3167. (https://doi.org/10.2337/ diacare.26.11.3160)

20 Higgins JP, Thompson SG, Deeks JJ \& Altman DG. Measuring inconsistency in meta-analyses. BMJ 2003327 557-560. (https://doi. org/10.1136/bmj.327.7414.557)

21 Roy CN, Snyder PJ, Stephens-Shields AJ, Artz AS, Bhasin S, Cohen HJ, Farrar JT, Gill TM, Zeldow B, Cella D, et al. Association of testosterone levels with anemia in older men: a controlled clinical trial. JAMA Internal Medicine 2017177 480-490. (https://doi.org/10.1001/ jamainternmed.2016.9540)

22 Camacho EM, Huhtaniemi IT, O’Neill TW, Finn JD, Pye SR, Lee DM, Tajar A, Bartfai G, Boonen S, Casanueva FF, et al. Age-associated changes in hypothalamic-pituitary-testicular function in middle-aged and older men are modified by weight change and lifestyle factors: longitudinal results from the European Male Ageing Study. European Journal of Endocrinology 2013168 445-455. (https://doi.org/10.1530/ EJE-12-0890) https://ec.bioscientifica.com https://doi.org/10.1530/EC-18-0514
(C) 2019 The authors Published by Bioscientifica Ltd

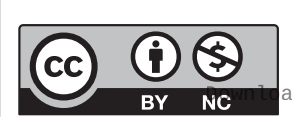

This work is licensed under a Creative Commons Attribution-NonCommercial 4.0 International License. ded from Bioscientifica com at 04/26/2023 02:14:45AM 
23 Tsametis CP \& Isidori AM. Testosterone replacement therapy: for whom, when and how? Metabolism: Clinical and Experimental 2018 86 69-78. (https://doi.org/10.1016/j.metabol.2018.03.007)

24 Seftel AD, Mack RJ, Secrest AR \& Smith TM. Restorative increases in serum testosterone levels are significantly correlated to improvements in sexual functioning. Journal of Andrology 200425 963-972. (https://doi.org/10.1002/j.1939-4640.2004.tb03169.x)

25 Wu F, Zitzmann M, Heiselman D, Donatucci C, Knorr J, Patel AB \& Kinchen K. Demographic and clinical correlates of patient-reported improvement in sex drive, erectile function, and energy with testosterone solution 2. Journal of Sexual Medicine 201613 1212-1219. (https://doi.org/10.1016/j.jsxm.2016.05.010)

26 Giagulli VA, Kaufman JM \& Vermeulen A. Pathogenesis of the decreased androgen levels in obese men. Journal of Clinical Endocrinology and Metabolism 199479 997-1000. (https://doi. $\operatorname{org} / 10.1210 /$ jcem.79.4.7962311)

27 Vermeulen A, Kaufman JM \& Giagulli VA. Influence of some biological indexes on sex hormone-binding globulin and androgen levels in aging or obese males. Journal of Clinical Endocrinology and Metabolism 199681 1821-1826. (https://doi.org/10.1210/ jcem.81.5.8626841)

28 Michalakis K, Mintziori G, Kaprara A, Tarlatzis BC \& Goulis DG. The complex interaction between obesity, metabolic syndrome and reproductive axis: a narrative review. Metabolism: Clinical and Experimental 201362 457-478. (https://doi.org/10.1016/j. metabol.2012.08.012)

29 Burcelin R, Thorens B, Glauser M, Gaillard RC \& Pralong FP. Gonadotropin-releasing hormone secretion from hypothalamic neurons: stimulation by insulin and potentiation by leptin. Endocrinology 2003144 4484-4491. (https://doi.org/10.1210/ en.2003-0457)

30 Jeibmann A, Zahedi S, Simoni M, Nieschlag E \& Byrne MM. Glucagon-like peptide- 1 reduces the pulsatile component of testosterone secretion in healthy males. European Journal of Clinical Investigation 200535 565-572. (https://doi.org/10.1111/j.13652362.2005.01542.x)

31 Pi-Sunyer X, Astrup A, Fujioka K, Greenway F, Halpern A, Krempf M, Lau DC, le Roux CW, Violante Ortiz R, Jensen CB, et al. A randomized, controlled trial of $3.0 \mathrm{mg}$ of liraglutide in weight management. New England Journal of Medicine 2015373 11-22. (https://doi.org/10.1056/NEJMoa1411892)

32 Davies MJ, Bergenstal R, Bode B, Kushner RF, Lewin A, Skjoth TV, Andreasen AH, Jensen CB, DeFronzo RA \& NN8022-1922 Study Group. Efficacy of liraglutide for weight loss among patients With Type 2 diabetes: the SCALE diabetes randomized clinical trial. JAMA 2015314 687-699. (https://doi.org/10.1001/jama.2015.9676)

33 Blackman A, Foster GD, Zammit G, Rosenberg R, Aronne L, Wadden T, Claudius B, Jensen CB \& Mignot E. Effect of liraglutide $3.0 \mathrm{mg}$ in individuals with obesity and moderate or severe obstructive sleep apnea: the SCALE Sleep Apnea randomized clinical trial. International Journal of Obesity 201640 1310-1319. (https://doi. org/10.1038/ijo.2016.52)

34 Jones TH, Arver S, Behre HM, Buvat J, Meuleman E, Moncada I, Morales AM, Volterrani M, Yellowlees A, Howell JD, et al.
Testosterone replacement in hypogonadal men with type 2 diabetes and/or metabolic syndrome (the TIMES2 study) Diabetes Care 2011 34 828-837. (https://doi.org/10.2337/dc10-1233)

35 Hackett G, Cole N, Bhartia M, Kennedy D, Raju J \& Wilkinson P. Testosterone replacement therapy with long-acting testosterone undecanoate improves sexual function and quality-of-life parameters vs. placebo in a population of men with type 2 diabetes. Journal of Sexual Medicine 201310 1612-1627. (https://doi.org/10.1111/ jsm.12146)

36 Corona G, Monami M, Rastrelli G, Aversa A, Sforza A, Lenzi A, Forti G, Mannucci E \& Maggi M. Type 2 diabetes mellitus and testosterone: a meta-analysis study. International Journal of Andrology 201134 528-540. (https://doi.org/10.1111/j.13652605.2010.01117.x)

37 Hackett G, Cole N, Bhartia M, Kennedy D, Raju J, Wilkinson P \& BLAST Study Group. Testosterone replacement therapy improves metabolic parameters in hypogonadal men with type 2 diabetes but not in men with coexisting depression: the BLAST study. Journal of Sexual Medicine 201411 840-856. (https://doi.org/10.1111/ jsm.12404)

38 Corona G, Giagulli VA, Maseroli E, Vignozzi L, Aversa A, Zitzmann M, Saad F, Mannucci E \& Maggi M. THERAPY OF ENDOCRINE DISEASE: Testosterone supplementation and body composition: results from a meta-analysis study. European Journal of Endocrinology 2016174 R99-R116. (https://doi. org/10.1530/EJE-15-0262)

39 Wang C, Jackson G, Jones TH, Matsumoto AM, Nehra A, Perelman MA, Swerdloff RS, Traish A, Zitzmann M \& Cunningham G. Low testosterone associated with obesity and the metabolic syndrome contributes to sexual dysfunction and cardiovascular disease risk in men with type 2 diabetes. Diabetes Care 201134 1669-1675. (https://doi. org/10.2337/dc10-2339)

40 Wang C, Nieschlag E, Swerdloff R, Behre HM, Hellstrom WJ, Gooren LJ, Kaufman JM, Legros JJ, Lunenfeld B, Morales A, et al. Investigation, treatment and monitoring of late-onset hypogonadism in males: ISA, ISSAM, EAU, EAA and ASA recommendations. European Journal of Endocrinology 2008159 507-514. (https://doi.org/10.1530/ EJE-08-0601)

41 Singh R, Artaza JN, Taylor WE, Gonzalez-Cadavid NF \& Bhasin S. Androgens stimulate myogenic differentiation and inhibit adipogenesis in C3H 10T1/2 pluripotent cells through an androgen receptor-mediated pathway. Endocrinology 2003144 5081-5088. (https://doi.org/10.1210/en.2003-0741)

42 Groti K, Zuran I, Antonic B, Forsnaric L \& Pfeifer M. The impact of testosterone replacement therapy on glycemic control, vascular function, and components of the metabolic syndrome in obese hypogonadal men with type 2 diabetes. Aging Male 201821 158-169. (https://doi.org/10.1080/13685538.2018.1468429)

43 Gianatti EJ, Dupuis P, Hoermann R, Zajac JD \& Grossmann M. Effect of testosterone treatment on constitutional and sexual symptoms in men with type 2 diabetes in a randomized, placebo-controlled clinical trial. Journal of Clinical Endocrinology and Metabolism 201499 3821-3828. (https://doi.org/10.1210/jc.2014-1872)

Received in final form 28 January 2019

Accepted 1 February 2019

Accepted Preprint published online 1 February 2019 https://ec.bioscientifica.com https://doi.org/10.1530/EC-18-0514 (c) 2019 The authors Published by Bioscientifica Ltd

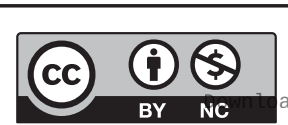

This work is licensed under a Creative Commons Attribution-NonCommercial 4.0 International License. ded from Bioscientifica com at 04/26/2023 02:14:45AM 